\title{
Evaluation of the Mechanical Properties of the Samples Made by FDM 3D Printing
}

\begin{abstract}
ALEXANDRU POPA*, NICOLAE FAUR*, MIHAI HLUSCU*, COSMIN BELIN*
Mechanics and Strength of Materials department, Politehnica University of Timisoara, 3 Victoriei Sq., 300006 Timisoara, Romania

Designing a sample to be made by FDM 3D printing is a fundamental problem in further studies related to such printed structures as material properties vary depending on filament orientation and G-code particularities. Samples designed to simulate wall structures inside 3D printed parts have been tested to allow separate evaluation of key components in such parts. Results show a very long plastic region in filaments without imperfections. As filament strands break steps of similar values appear in the reaction force measured by the machine.
\end{abstract}

Keywords: FDM 3d printing, filament, structure, strand

FDM 3D printing is the most accessible form of rapid prototyping. The evolution of this branch of rapid prototyping has been fast and inexpensive and it is still ongoing. The reason behind this phenomenon is the open-source nature of both the hardware and the software involved [1-3].

An interesting side effect of the accessibility to FDM 3D printing technology is the possibility of ad-hoc tinkering. There are numerous blogs and video channels dedicated to this topic and doing basic to complicated experiments [2-4].

In the academic world, papers on FDM 3D printing are mostly approaching the topic from the same point of view as they do any other form of rapid prototyping - a CNC machine that performs material addition [4-8]. This academic approach is also similar in machining (material removal). The reasoning behind this approach being that all of the above are CNC machines thateither add or remove material. This reasoning is correct as any advance in CNC and related technologies will positively impact all the applications mentioned above.

In the case of FDM 3D printing, however, there are intricacies specific to this application that have not been studied in enough detail or isolated appropriately $[2,4,6$, 7]. Most of these intricacies stem from the fact that FDM 3D printed parts are rarely, in practice, solid objects [3, $9,10]$. While we can produce parts and samples completely filled with material there is never a compelling reason to do so with this particular technology [11-13].

On the topic of appropriate isolation of intricacies is the lack of consistency on how the filament orientation should be in standard test specimens [9]. Filament orientations in FDM 3D printed parts are entirely decided by the G-Code optimization algorithm which means that a test specimen will not represent the real part [14]. Geometrical anisotropy is present in both real part and test sample, butit is different in one from the other $[12,13,15]$. The geometrical anisotropy resulting from filament orientation of an FDM $3 \mathrm{D}$ printed standard tensile test specimen is undefined in any standard $[10,15]$. The tensile test specimen is not the only example here as any other test specimen will be undefined from this point of view when created by FDM 3D printing.

A better abstraction of FDM 3D printed parts is a shell of multiple filament thicknesses with an internal structure of 1 filament thickness as reinforcement to achieve the desired rigidity [9]. This paper describes and analyzes test specimens that can help quantify the properties of key structures found in an FDM 3D printed part.

\section{Experiments parts}

$3 D$ printing configuration and tools

For 3D printing the samples the FDM printer Leapfrog Bolt Pro [16] (Fig. 1) has been used. The material used was PLA Filament- RBX-PLA-BK092 'Black as Night' [17].

The printing parameters can be seen in Table 1 . The choice is a balance between speed and accuracy [1]

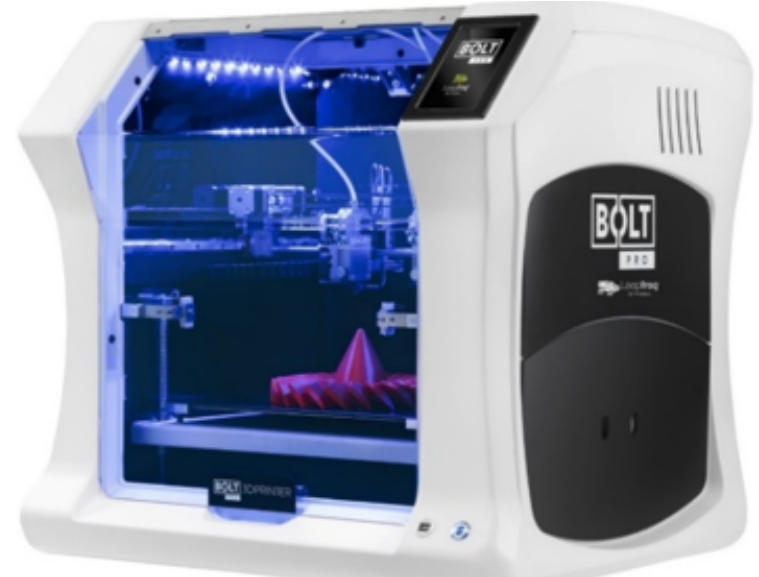

Fig. 1. The FDM printer Leapfrog Bolt Pro

Test equipment

For testing and analyzing the 3D printed samples the following tools were used:

-Instron 5967 Dual Column Series mechanical testing machine [18] (Fig. 2)

-Leica DMS1000 digital microscope [19] (Fig. 2)

\section{Samples}

The first attempt at sample design was based on the ASTM D638 Specimen. It had been redesigned to be fit for 3D printing and to allow testing of two distinct morphological parts of FDM 3D printed components however the 3D printing process created stress concentrators in the parts due to the automatically generated G-Code 
Table 1

THE PRINTING PARAMETERS

\begin{tabular}{|c|c|c|c|}
\hline \multicolumn{2}{|c|}{ Extruder } & \multicolumn{2}{|l|}{ Layer } \\
\hline Nozzle Diameter & $0.35 \mathrm{~mm}$ & Primary Layer Height & $0.24 \mathrm{~mm}$ \\
\hline Extrusion Multiplier & 0.95 & Top Solid Layers & 6 \\
\hline Retraction Distance & $2 \mathrm{~mm}$ & Bottom Solid Layers & 5 \\
\hline Extra Restart Distance & Omm & Outline/Perimeter Shells & 2 \\
\hline Retraction Vertical Lift & $0.4 \mathrm{~mm}$ & Outline Direction & Outside-in \\
\hline Retraction Speed & $3000 \mathrm{~mm} / \mathrm{min}$ & First Layer Height & $80 \%$ \\
\hline \multirow[t]{2}{*}{ Coasting Distance } & $0.29 \mathrm{~mm}$ & First Layer Width & $120 \%$ \\
\hline & & First Layer Speed & $50 \%$ \\
\hline \multicolumn{2}{|c|}{ Infill } & \multicolumn{2}{|l|}{ Speeds } \\
\hline Interior Fill Percentage & $40 \%$ & Default Printing Speed & $3600 \mathrm{~mm} / \mathrm{min}$ \\
\hline Internal Fill Pattern & Rectilinear & Outline Underspeed & $40 \%$ \\
\hline External Fill Pattern & Rectilinear & Solid Infill Underspeed & $80 \%$ \\
\hline Outline Overlap & $40 \%$ & Support Structure Underspeed & $80 \%$ \\
\hline Infill Extrusion Width & $150 \%$ & $\mathrm{X} / \mathrm{\gamma}$ Axis Movement Speed & $12000 \mathrm{~mm} / \mathrm{min}$ \\
\hline Minimum Infill Length & $5 \mathrm{~mm}$ & Z Axis Movement Speed & $1002 \mathrm{~mm} / \mathrm{min}$ \\
\hline Combine Infill Every & 1 layers & Adjust printing speed for layers below & $15 \mathrm{sec}$ \\
\hline Internal Infill Angle Offsets & $45^{\circ},-45^{\circ}$ & Allow speed reductions down to & $20 \%$ \\
\hline External Infill Angle Offsets & $45^{\circ},-45^{\circ}$ & & \\
\hline \multicolumn{2}{|c|}{ Temperature } & & \\
\hline Right Extruder & $210^{\circ} \mathrm{C}$ & & \\
\hline Heated Bed & $50^{\circ} \mathrm{C}$ & & \\
\hline
\end{tabular}
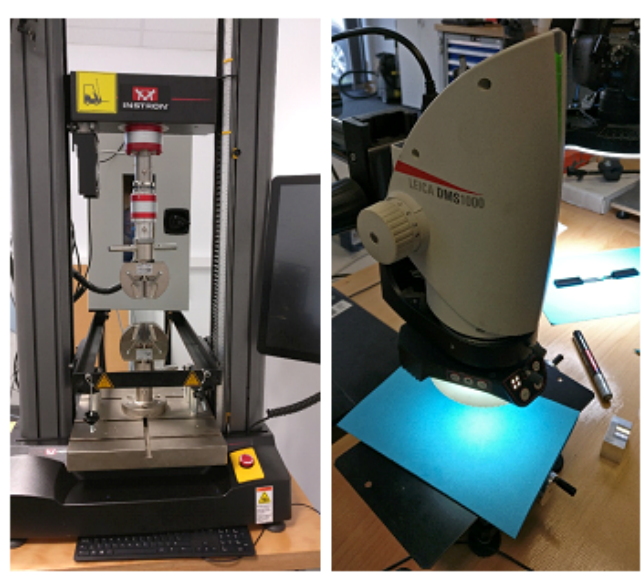

Fig. 2. Instron 5967 Dual Column Series testing machine and Leica DMS1000 Digital Microscope

To overcome this issue a hexagon with dense structural walls was 3D printed and specimens were cut-out of the part (Fig. 3). The hexagon was designed to mimic a typical 3D printed part with structural walls as infill but with the particularity of parallelism between the walls to allow removal of individual pieces.

The cut-out specimens were 3 frayed structural walls $(0.4 \mathrm{~mm}$, frayed due to printing defect), 3 structural walls $(0.4 \mathrm{~mm}$, no defect), 1 external wall of 1 filament thickness $(0.4 \mathrm{~mm})$ and 1 external wall of 2 filament thicknesses $(0.8 \mathrm{~mm})$. These can be seen in figure 4 .

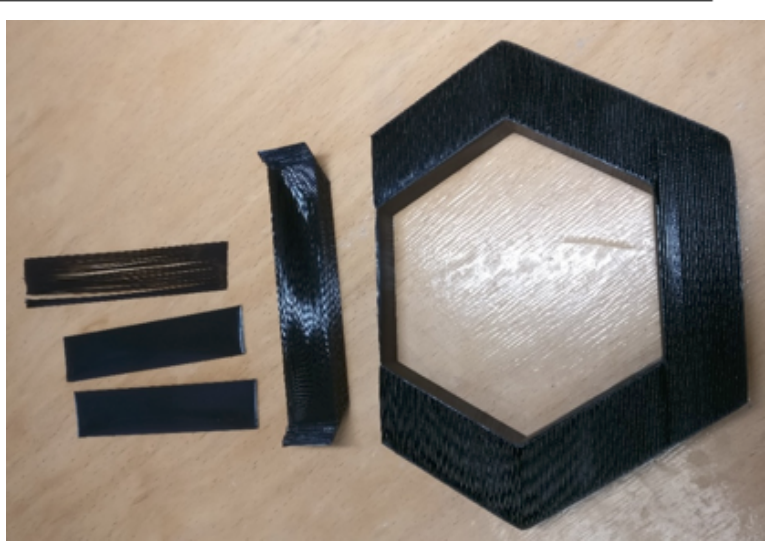

Fig. 3. Hexagonal 3D printed part with specimens cut out of it

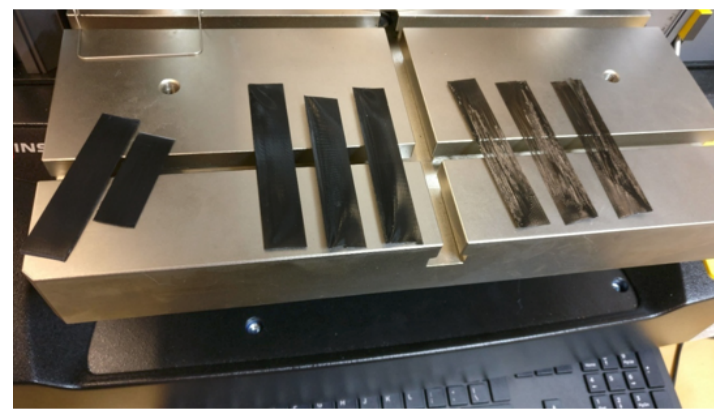

Fig. 4. Overview of cut out specimens 


\section{Results and discussions}

Table 2 contains the summary of the test results including the relevant charts and reference data for all tested specimens.

The first observation, on the topic of 3D printed components, is the presence of weak points throughout the structure. Such weak points interfere with testing of the fused material and appear due to the printer nozzle changing directions [11-14]. An observable example of this phenomenon can be seen in figure 8. Due to the merging of 3 contours of filament the resultin this particular case is the visible weak point between the thin wall and the tip of the solid part. This is the main reason behind the failure to test samples based on the ASTM D638 Specimen as strips of material cannot be attached properly to solid blocks of material. The drawback of testing strips of material is that shearing at the edge of the grippers has nullified half of the tests. To be noted that the strip seen below the weak point has been removed and tested separately with results equivalent to Sample 4.

The second observation is on the topic of frayed walls (Fig. 5). It can be seen in the successful tests that steps in force appear at the end of the test due to individual strands breaking. This phenomenon allows the measurement of the average tensile strength of a strand of fused filament without strengthening effects that can appear when the strands are also fused one to another. By analyzing the force steps starting from $57 \mathrm{~mm}$ displacement until the end of the test $(140 \mathrm{~mm})$ in figure 5, Sample 1 there can be measured 14 steps of approximately equal value. The average force drop between steps is $2.35 \mathrm{~N}$ with the values being $2.1 \mathrm{~N} ; 2.4 \mathrm{~N} ; 2.2 \mathrm{~N} ; 2.1 \mathrm{~N} ; 3.3 \mathrm{~N} ; 2.5 \mathrm{~N} ; 2.1 \mathrm{~N} ; 2.1 \mathrm{~N} ; 2.3 \mathrm{~N}$; $2.5 \mathrm{~N} ; 2.2 \mathrm{~N} ; 2.7 \mathrm{~N} ; 2.3 \mathrm{~N} ; 2.1 \mathrm{~N}$. Considering that force variation is within $+/-0.1 \mathrm{~N}$ on the same step we can assume that the average force drop represents the force at which a filament strand elongates in the plastic region of its strain-displacement curve. As they reach their maximum elongation in succession due to different lengths and gripping conditions strands snap creating the steps. The same measurement has been performed for figure 5, Sample 3 resulting in an average force of $2.16 \mathrm{~N}$ from 9 steps with the values being $2.5 \mathrm{~N} ; 2.1 \mathrm{~N} ; 2.1 \mathrm{~N} ; 2.2 \mathrm{~N}$; $2.2 \mathrm{~N} ; 2.1 \mathrm{~N} ; 2.1 \mathrm{~N} ; 2.1 \mathrm{~N} ; 2.1 \mathrm{~N}$. The average of all values is $2.27 \mathrm{~N}$ and this represents the average force at which a strand of filament extruded from a $\varnothing 0.4 \mathrm{~mm}$ printer nozzle elongates in the plastic region of its strain-displacement curve.

The third observation, on the topic of normal walls, is the high elongation at constant force present in the successful tests done on one normal structural wall strip and one double filament thickness external wall. The behavior can be seen in figure 6 , Sample 4 for the structural

Table 2

SUMMARY OF THE TEST RESULTS

\begin{tabular}{|c|c|c|c|c|}
\hline Sample & Speed & Type & Chart & Notes during experiment \\
\hline 1 & $20 \mathrm{~mm} / \mathrm{min}$ & Frayed & Figure 5 & Visible force steps as individual strands break \\
\hline 2 & $20 \mathrm{~mm} / \mathrm{min}$ & Frayed & Figure 5 & $\begin{array}{l}\text { Taped together for better machine gripping but slipped out of } \\
\text { tape }\end{array}$ \\
\hline 3 & $20 \mathrm{~mm} / \mathrm{min}$ & Frayed & Figure 5 & $\begin{array}{l}\text { Visible force steps as individual strands break but many } \\
\text { broken at initial pull }\end{array}$ \\
\hline 4 & $20 \mathrm{~mm} / \mathrm{min}$ & Normal & Figure 6 & Specimen is elongating at constant force, ductile breaking \\
\hline 5 & $20 \mathrm{~mm} / \mathrm{min}$ & Normal & Figure 6 & Shearing at machine gripping point, no conclusion \\
\hline 6 & $20 \mathrm{~mm} / \mathrm{min}$ & Normal & Figure 6 & Shearing at machine gripping point, no conclusion \\
\hline Strip & $10 \mathrm{~mm} / \mathrm{min}$ & Normal & Figure 6 & $\begin{array}{l}\text { Strip preserved from failed attempt at the ASTM D638 } \\
\text { Specimen. See Figures } 8,10 \text {. } \\
\text { Elongated at constant force. }\end{array}$ \\
\hline 7 & $20 \mathrm{~mm} / \mathrm{min}$ & $\begin{array}{l}\text { External } \\
0.4 \mathrm{~mm}\end{array}$ & Figure 7 & Shearing at machine gripping point, no conclusion \\
\hline 7 & $20 \mathrm{~mm} / \mathrm{min}$ & $\begin{array}{l}\text { External } \\
0.4 \mathrm{~mm}\end{array}$ & Figure 7 & $\begin{array}{l}\text { Repeat test on one remaining half. Shearing at machine } \\
\text { gripping point, no conclusion }\end{array}$ \\
\hline 8 & $20 \mathrm{~mm} / \mathrm{min}$ & $\begin{array}{l}\text { External } \\
0.8 \mathrm{~mm}\end{array}$ & Figure 7 & Shearing at machine gripping point, no conclusion \\
\hline 8 & $20 \mathrm{~mm} / \mathrm{min}$ & $\begin{array}{l}\text { External } \\
0.8 \mathrm{~mm}\end{array}$ & Figure 7 & $\begin{array}{l}\text { Repeat test on one remaining half. Specimen is elongating at } \\
\text { constant force, ductile breaking. }\end{array}$ \\
\hline
\end{tabular}

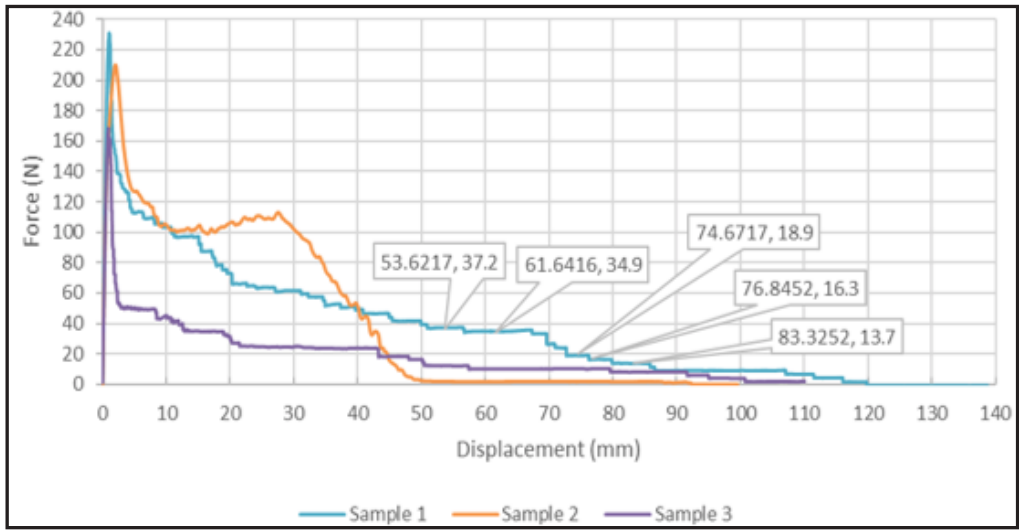

Fig.5. Frayed samples 


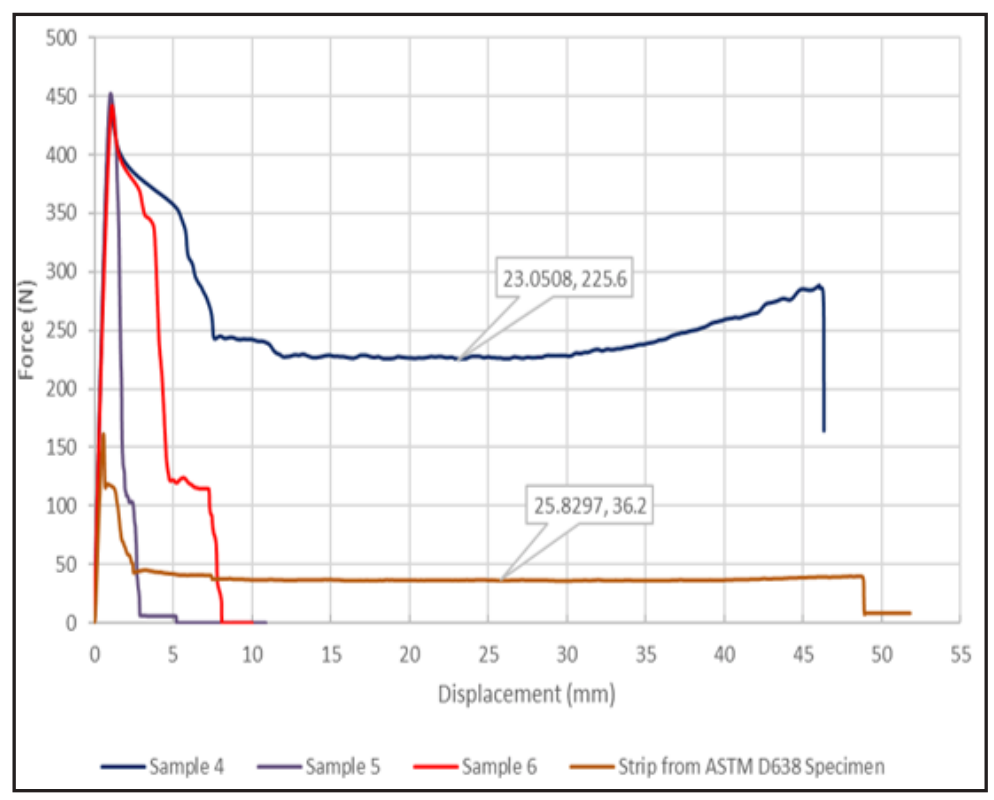

Fig.6 Normal samples

wall and figure 7, Sample 8 2 for the external wall. Figure 9 shows the visual aspect of the high elongation and allows the counting of filament strands fused in the strip.

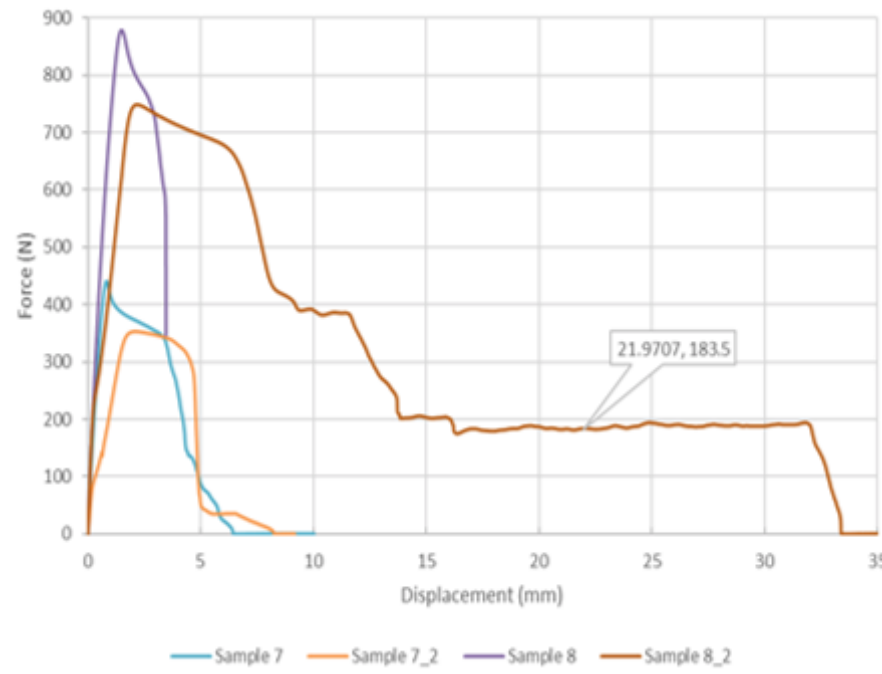

Fig.7 External walss

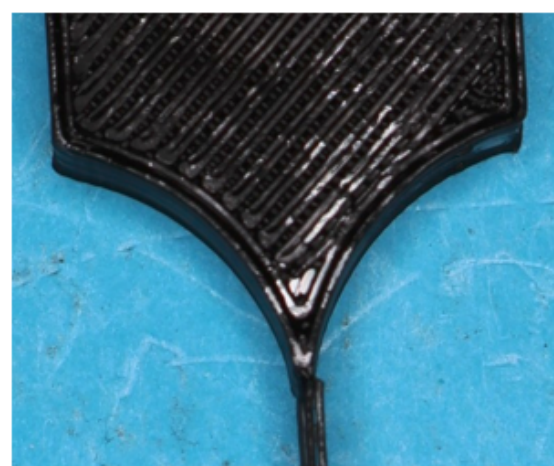

Fig. 8. Sample based on ASTM D638 with weak point

On visual inspection of Sample 4 after the test it can be observed that only the central region of the elongated strands was load bearing during the pass into the plastic region seen in figure 6 . The two strands seen on the right side of the Sample 4 picture in figure 9 are not completely elongated and most likely represent the small dip in force observed at $12 \mathrm{~mm}$ displacement. The average force recording between the displacement values of $15 \mathrm{~mm}$ to $25 \mathrm{~mm}$ is $226.9 \mathrm{~N}$. The load bearing region contains 81 strands, 79 of which are fused on two sides and 2 of which are fused only on one side. The cross-section of the strip is composed of 81 strands of filament and 80 fused connections between them. The average strand and corresponding fused connections elongate in the plastic region of their strain-displacement curve at $2.8 \mathrm{~N}$.

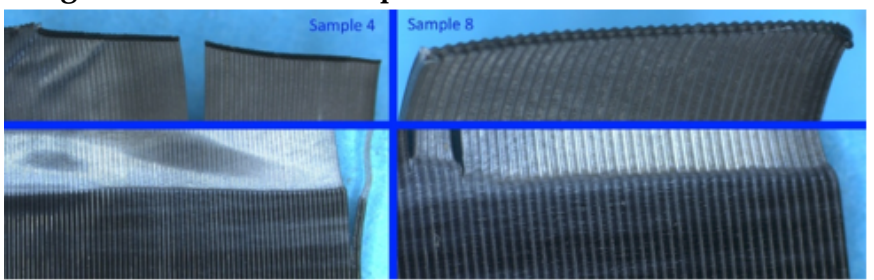

Fig. 9. Samples 4 (left) and 8 (right) after high plastic elongation

Similar results have been obtained from the strip removed from the ASTM D638 Specimen design attempt. The average force measured between $10 \mathrm{~mm}$ to $30 \mathrm{~mm}$ displacement on figure 6, ASTM D638 Specimen is 36.48N. The constant force measured between $49 \mathrm{~mm}$ to $51 \mathrm{~mm}$ displacement measured in the same graph is $8.3 \mathrm{~N}$ and is given by a survivor strand which detached from the strip (fig. 10). The difference between these two averages is $28.18 \mathrm{~N}$ which is the force at which the main part of the strip formed of 10 fused strands elongate in the plastic region of their strain-displacement curves. The average force per strand and corresponding fused connections is therefore $2.81 \mathrm{~N}$.

For Sample 82 the average of the registered constant force is $187 . \overline{1} 5 \mathrm{~N}$ between $20 \mathrm{~mm}$ and $30 \mathrm{~mm}$ displacement. The strand count on one side is 38 and therefore the total strand count in the elongated region is 76 fused filament strands. The average strand and corresponding fused connections elongate in the plastic region of their strain-displacement curve at $2.46 \mathrm{~N}$.

\section{Conclusions}

The strip samples are adequate for measuring filament strand properties due to successfully but inadequate for gripping in the testing machine. Using a higher number of samples can overcome this problem. Due to the presence of filament strands in all walls of an 3D FDM printed part it is possible to extract test samples and have comparable results from most such parts.

Strips and other structures composed of parallel filament strands act as multiple specimens being tested at the same time. This allows the reduction of sample sizes without skewing the results of statistical analyses. While advanced 


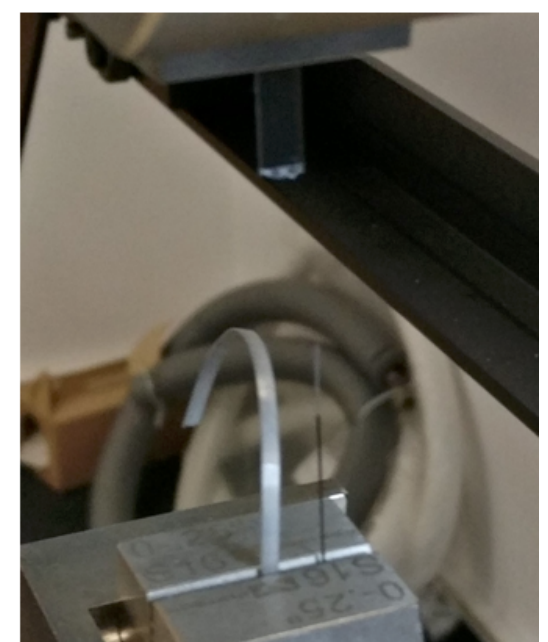

Fig. 10. Strip removed from ASTM D638 specimen (Fig. 8) after high plastic elongation

statistical analyses have not been performed in this paper there was enough raw data in the frayed sample tests to demonstrate the consistency of the breaking force of individual strands.

Filament strand properties were measured with the following results:

- elongation in the plastic region at constant force of 2.27N per standalone filament strand;

- elongation in the plastic region at constant force of $2.81 \mathrm{~N}$ per fused strand in a wall of 1 filament strand thickness;

- elongation in the plastic region at constant force of $2.46 \mathrm{~N}$ per fused strand in a wall of 2 filament strand thickness;

- while the average values given at point 2 are valid for the selected material and $3 \mathrm{D}$ printing parameters a more general conclusion is that a structural wall of fused filament strands can withstand a $23.8 \%$ higher load than its individual strands unfused.

A double wall of fused filament strands can withstand an $8.4 \%$ higher load than its individual strands unfused.

\section{References}

1.GALANTUCCI, L.M., BODI, I., KACANI, J., LAVECCHIA, F., Procedia Cirp, Vol. 28, 2014, p. 82

2.VASILESCU, M.D., FLESER, T., Influence of Technological Parametrson the Dimesion of Gear Parts Generated with PLA Matherial by FDM3D Printing, Mat Plast., 55 no. 2, 2018, p. $247-251$
3.NEDELCU, D., COJ OCARU, V., MICU, L.M., FLOREA, D., HLUSCU, M., Using of Polymers for Rapid Prototyping of an Axial Microturbine Runner and Wicked Gates, Mat. Plast. 56 , no.2, 2019, p.454-459

4.VASILESCU, M.D., Constructiv and Technological Consideration on the Generation of Gear Made by the DLP 3D-Printed Methode, Mat. Plast. 56, no. 2, 2019, p.440-444

5.ANTON, L. E., BORDEASU, I., TABARA, I., Considerations regarding the use of EPO $99 \mathrm{~B}$ resin in manufacturing AXIAL hydraulic machinery runners, Mat. Plast. 45, no. 2, 2008, p.190-192

6.POPESCU, A., ENCIU, G., DOBRESCU, T., PASCU, N. E., ExperimentalResearch Using the 3D Printing Technology with Plastic Materials for Prehension Systems Jaws, Mat Plast., 55, no. 1, 2018, p. 20-23

7.MITELEA, I., MICUL, L.M., BORDEASU, I., CRACIUNESCU, C.M., Journal of Materials Engineering and Performance, vol. 25, Issue 5, 2016, p.1939-1944

8.PRODAN, D., BUCURESTEANU, A., MOTOMANCEA, A., Constructionof Plastic Parts on CNC Engraving Machines and $3 D$ Printers, Mat.Plast., 55, no.1, 2018, p.75-78,

9.MOHAMED, O.A., MASOOD, S.H., BHOWMIK, J.L., Advances in Manufacturing, Vol. 3 Issue 1, 2015, p. 42

10.MASOOD, S.H., MAU, K., SONG, W.Q., Materials Science Forum, Vols. 654-656, 2010, p. 2556

11.ILIESCU, N., ATANASIU, C., HADAR, A., The simulation of the mechanical behaviour of engineering structures on models made of plastic materials with special properties, Mat. Plast. 42, no. 1, 2005, p.72-76

12.TABACU, S., HADAR, A., MARINESCU, D., IVANESCU, M., BALASOIU, V., Numerical Procedures for the Improvement of the Structural Response of Thermoplastic Manufactured Parts,Mat. Plast. 46, no. 2, 2010, p.192-197

13.MITELEA, I., BORDEASU, I., HADAR, A., Rev. Chim.(Bucharest), 56, no. 11, 2005, p.1169-1174

14.BELLINI, A., GUCERI, S., Rapid Prototyping J ournal, Vol. 9 Issue 4, 2003, p. 252

15.AHN, S.H., MONTERO, M., ODELL, D., ROUNDY, S., WRIGHT, P. K., Rapid Prototyping J ournal, Vol. 8, Issue 4, 2002, p. 248

16.***https://www.Ipfrg.com/products/leapfrog-bolt-pro/

17.***http://www.cel-robox.com/wp-content/uploads/MSDS/Robox\%20

SmartReel\%20-\%20PLA\%20-\%20All\%20Colours\%20-\%20MSDS \%20Ver1.4.pdf

18.***https://www.instron.com/-/media/literature-library/products/ 2013/02/5960-series-dual-column-tabletop-5kn-50kn.pdf?la=en 19.***https://downloads.leica-microsystems.com/Leica\%20DMS1000/ Brochures/Leica_DMS1000\%20Brochure_EN.pdf

Manuscript nreceived: 17.06 .2019 